\title{
THE DEMOGRAPHIC REVOLUTION IS CHANGING THE REPRODUCTIVE STRATEGY OF HOMO SAPIENS * ANATOLY VISHNEVSKY
}

The demographic revolution (demographic transition) is changing the reproductive strategy of the species Homo sapiens. The whole evolution of life on Earth, including social evolution since the beginning of human society, has led to this triumph of the K-strategy of reproduction. This universal revolution has a crucial importance for the present stage of human history. The cause-and-effect relationship between economic, social and demographic changes is discussed, the interpretation of changes in the mass reproductive or family behavior as primarily a direct consequence of economic, social or cultural shifts is contested. Such explanations are redundant since the main changes in demographic behavior are a response to the necessity of restoring the demographic equilibrium upset by an unprecedented decline in mortality. At the same time, such explanations lead to an underestimation of the impact of demographic change on economic, social and cultural dimensions of the development of modern societies.

The demographic transition theory in its present form hinders the vision of this transition as an integral stand-alone process that has its own internal determinants and at the same time has a powerful impact on all social processes, including processes at the global level. The global logic of demographic transition theory is opposed to the widespread local logic, according to which this theory must be justified by the experience of each state.

\begin{abstract}
An attempt is made to overcome the current fragmentation in the description of the demographic transition and its splitting into multiple "transitions" and "revolutions", and to consider it as a cohesive process, that is, a sequence of inevitable major stages of a single global "chain reaction” initiated by an enormous decline in mortality.
\end{abstract}

Key words: demographic revolution, demographic transition; second demographic transition; third demographic transition; epidemiologic transition; fertility; mortality; migration.

\section{THE MEANING OF DEMOGRAPHIC TRANSITION}

Meaning the same as "demographic revolution", the term "demographic transition" is predominant in scientific literature, and we will use it in our article, although at the end of it we will state some considerations in favor of the first term.

For more than 100 years of development (if we start counting from Adolf Landry's article [Landry 1909]), the demographic transition theory has received very wide recognition. It is commonly used to explain and forecast demographic processes at all levels, from local to global, and despite the occasional criticism declaring it to be invalid, obsolete, etc. (see, for example, [Marchal 2008]), it is certainly one of the most respected social theories. Perhaps it is even broader than a middle-range theory suggested by D. Cowgill [1970: 633].

\footnotetext{
AnAtoly G. ViShnevSKy. Institute of Demography, National ReSEARCh University Higher SchoOl OF ECONOMICS. E-MAIL: avishnevsky@hse.ru.

TRANSLATED FROM: ДЕМОГРАФИЧЕСКОЕ ОБОЗРЕНИЕ. 2014, 1(1): 6-33. ORIGINAL TITLE: “ДЕМОГРАФИЧЕСКАЯ РЕВОЛЮЦИЯ МЕНЯЕТ РЕПРОДУКТИВНУЮ СТРАТЕГИЮ ВИДА НОMO SAPIENS” (HTTР://DEMREVIEW.HSE.RU/EN/2014-1/120991102.HTML).

* The study was implemented under the Basic Research Program at the National Research University, HigHER SCHOOL OF ECONOMICS (HSE) IN 2013-2014.
} 
However, widespread recognition that can play nasty trick on a person can be pernicious for a theory as well. It leads to the theory's spreading in scope rather than in depth, to its trivialization and use to describe the observed facts rather than to understand them. This results in the underestimation of the heuristic capabilities of the theory even by its supporters, not to mention its superficial critics.

Most authors settle for the definition of demographic transition as a movement from equilibrium of high mortality and high fertility to equilibrium at a low level of both, and reduce the theory to a "model" describing different stages of this movement. Different authors name a different number of such stages $(4,5$ or 6$)$, discuss factors operating at each of them, fertility and mortality levels separating one stage from another, and concentrate on how and when different countries pass through these stages (the demographic transition is described in such a way, for example, in Wikipedia articles meant for general readers). Usually, such authors attach special importance to quantitative indicators of the transition.

All of this facilitates the orderly description of the observed facts and trends, but not an understanding of the deep changes behind them, which under such an approach commonly fall outside the field of view of researchers. In this article we are primarily interested in the qualitative changes making up the essence of the demographic transition and widening the range of its effects far beyond purely quantitative changes.

Unfortunately, an interest in the essence of qualitative changes can hardly be ascribed to the mainstream of research literature on the demographic transition, although that is not to say that it is completely absent from the literature. I could refer, in particular, to my own book published long ago and repeating within the title the title of A. Landry's book [Vishnevsky 1976] as well as to my earlier article with the same title [Vishnevsky $1973 \mathrm{a}^{1}$ ]. I wrote, inter alia, that "the most important thing in the demographic revolution is profound qualitative changes in the entire system of demographic control, and thus in the demographic process" [quot. from Vishnevsky 2005: 199]. Pointing to the transition from high fertility and mortality to low levels of both, I noted that "the human population reproduction rises to a higher qualitative level: it becomes much more rational, efficient, and cost-effective" [Vishnevsky 1973: 59]. But I like most the definition given by M. Livi Bacci: "The demographic transition can be characterized as a change in the system, as a transition from a "dissipative" system related to the loss of demographic power (high fertility and mortality) to a system "economizing" this energy (low fertility and mortality)" [Livi Bacci 1995: 451].

Adding just a few words, without significantly affecting the scope of the definition, turns it from a purely descriptive to an explanatory notion, because it points to the evolutionary inequality of the pre- and post-transition situations and thereby provides the definition with a universality similar to that of physical laws.

Conceived in such a way, the transition to a new type of demographic equilibrium is an unprecedented and unique event in history. In fact, it changes the conditions for the existence of humans as a species. Humans themselves are not changed in terms of biology, but undergo

\footnotetext{
${ }^{1}$ The article was also published in English, French and German (twice) [Vishnevsky 1973b, 1974a, 1974b, 1980].
} 
fundamental changes in the reproduction characteristics of human populations, and these characteristics are also considered inherent properties of the species.

In 1967, American ecologists Robert MacArthur and Edward Wilson [MacArthur, Wilson 1967] proposed to distinguish between two fundamentally different strategies of population reproduction in nature: the $\boldsymbol{r}$-strategy and the $\boldsymbol{K}$-strategy ( $\boldsymbol{r}$ and $\boldsymbol{K}$ are parameters of Verhulst's logistic equation). Without going into details, the $\boldsymbol{r}$-strategy involves highly "wasteful" reproduction, a huge propagation of offspring, most of whom are doomed to an early death, so that only an insignificant part of them survives until the next reproduction cycle. On the contrary, the $\boldsymbol{K}$-strategy is economical; offspring are small in number, but characterized by much better survival. Fish spawn millions of eggs, while the offspring of mammals number in the dozens or even less. Yet, although the population size in nature varies over long periods, in total it does not change much, and the number of individuals surviving until their own procreation cycle remains more or less constant for each population, regardless of the species.

In reality, no population in nature adheres only to the $\boldsymbol{K}$-strategy; $\boldsymbol{r}$-strategy elements are always observed as well. Yet, in general, biological evolution is characterized by a tendency towards strengthening the $\boldsymbol{K}$-strategy. Species higher up on the evolutionary ladder are not highly dependent on external factors, because internal regulators of population dynamics play an increasingly important role. Their population size becomes more stable and the amplitude of its variation decreases. Their number may vary a few times over, but not by the hundreds, thousands or even millions of times that is characteristic for many insects and crustaceans.

The increasing role of internal regulators indicates an improvement in the efficiency of a species' reproduction, as well as a species' ability to use vital resources for other purposes than producing offspring. As a result, the organization and functioning of organisms and their communities becomes more complex.

With the appearance of human society, the protective mechanisms created by nature are supplemented with social protection mechanisms, and the "price" of population reproduction [Vishnevsky 2005: 184] decreases even further, which signifies a new step from the $\boldsymbol{r}$-strategy to the $\boldsymbol{K}$-strategy. This expands enormously the scope of freedom and the opportunities for the development of human society, serving as one of the main, if not the main, prerequisites for the appearance of human civilization.

For tens of thousands of years of human history, the protective mechanisms on which the reproductive $\boldsymbol{K}$-strategy of human population was based gradually improved, while not undergoing fundamental changes. Mortality of Europeans in the middle of the second millennium CE differed little from that of pre-Neolithic hunters and gatherers, and even less from that of representatives of ancient civilizations. The fundamental breakthrough began only at the end of the eighteenth century and meant the real triumph of the $\boldsymbol{K}$-strategy - a sharp increase in population reproduction efficiency to the highest possible level. The $\boldsymbol{r}$-strategy elements virtually disappeared. 


\section{THE CHICKEN OR THE EGG?}

It is obvious that all these changes did not occur by themselves, but were the result of a thousand years of economic and social development of humankind. It is, however, quite possible that they became the most important, yet still unrecognized outcome. Historians and public opinion attach much more importance to political, economic or social changes of modern history, for instance, to global processes such as urbanization, industrial or technological revolution or the rise of postindustrial society, etc. Yet, only the new reproductive strategy of human populations, poorly seen in the background of all these other changes, affects the very foundations of the existence of the human species, and in this sense it is not just comparable to the greatest economic or political revolutions in its fundamental impact on the future, but most likely even exceeds them.

These demographic changes turned out to be so deep that they could not help but affect all aspects of people's lives, leaving a mark on all rules of human society, on the norms of social control and on culture. Everything must change and indeed does change, but recognizing the true causes of these changes is hard for theorists, due to their chronic underestimation of the independence of the demographic factor.

In the case of Russia, such underestimation was associated with the Marxist or rather pseudo-Marxist scientific tradition. As Engels wrote, "According to the materialistic conception, the determining factor in history is, in the final instance, the production and reproduction of the immediate essentials of life. This, again, is of a twofold character. On the one side, the production of the means of existence, of articles of food and clothing, dwellings, and of the tools necessary for that production; on the other side, the production of human beings themselves, the propagation of the species. The social organization under which the people of a particular historical epoch and a particular country live is determined by both kinds of production: by the stage of development of labor on the one hand and of the family on the other" [Engels, 1884]. Engels does not use the word "demography", which was little known at that time, but the fact that he puts "procreation" on a par with "production of the means of subsistence" can be interpreted as recognition of the independence and primary importance of what we now would call the demographic factor.

In the Soviet Union, despite the authority of Engels, this view was not popular. For some time, the above-given quotation of a "Marxist classic" was supplemented (rarest case) by a "corrective" editorial note: "Engels is not quite accurate here when equating the procreation and the production of the means of subsistence as causes contributing to the development of society and social orders" [Marx and Engels 1948: 160-161]. In fact, K. Kautsky's argument is repeated there without reference to the original source: "This is just a simple play on the word 'production' ... What Engels calls changes in the natural reproduction process - changes in forms of family and marriage $-\ldots$ are results, rather than driving forces of social evolution. All this is caused by changes not in the reproduction technique, but in the production technique of the means of subsistence.... Changes in this kind of production are, ultimately, the only ones that cause all changes in social forms and predefine history" [Kautsky 1923: 119].

After Stalin's death the editorial note disappeared from Engels' works, but not from the heads of Soviet researchers, who continued to fight against the "misconceptions about the selfcontained nature of demographic processes ... whereas in fact, these are regular demographic changes under the influence of socio-economic development" [Guzevaty 1980: 30]. 
Although Western theorists of the demographic transition were not, as a rule, Marxists and most likely did not know anything about the intra-Marxist controversy, their opinion was surprisingly consistent with that of Kautsky. According to George Caldwell, his own research in Africa and Asia showed that the type of economy affected the culture, religion and demographic behavior of the population in these countries. "Clearly, this is akin to Karl Marx's use of "mode of production", a term which will also be used here" [Caldwell 2006: 6]. Meanwhile, he interprets the "production of material life" in line with Kautsky, not Engels, and considers everything related to demography to be part of the 'superstructure', not the 'foundation'.

The very fact that the "demographic transition" or "demographic revolution" is regarded as a special historical phenomenon suggests, of course, a recognition of its epochal importance, but not always a recognition of its independent internal logic. "This internal logic does not attract the attention of demographers, who interpret such changes only as a result of various social shifts, which are non-demographic in their nature" [Vishnevsky 1991: 267].

A good illustration of this approach is the opposition between "descriptive" and "explanatory" aspects of the demographic transition theory by J.-C. Chesnais. The descriptive aspect "refers to internal dynamics of the population: it concerns the impact of mortality on fertility", which, according to Chesnais, was noted as early as in the nineteenth century; thus, the idea of transition "existed in embryo even then", but it was nothing more than a statement of fact. The explanatory aspect, especially when it comes to reducing fertility, requires recourse to socioeconomic, cultural, social, political, etc. determinants, which offer an "explanation" [Chesnais 1986: 6-8].

This view of the essence of the demographic transition has not been overcome even today. As is noted by David Reher in his recent article: “... Students of the demographic transition would want to see it as part of the larger process of economic and social modernization, with demographic change largely guided by social and economic change. Rather less attention has been given to the demographic transition specifically as a cause rather than as a consequence of this process of change. Ultimately, historians and social scientists tend to conceptualize demographic realities as determined by economic forces rather than the other way around. I argue here that in many ways demographic change can and should be seen as an essential factor of change. The demographic transition will be considered as a largely autonomous process that ended up having profound social, economic, and even psychological or ideational implications for society [Demeny 1972: 154]. Demography will be seen as an independent variable" [Reher 2011: 11-12].

Unfortunately, the current state of the demographic transition theory makes it difficult to view it as a complete, stand-alone process that has its own internal determination, and that actively influences all social processes, including those at the global level. With regards to understanding the true importance of the demographic transition as a fundamental shift in the reproductive strategy of humans as a species, as well as the inevitable consequences of this shift and its significance, there is still no sign of its existence.

This does not mean that the demographic transition theory has remained unchanged; over its hundred years of existence it has been subject to constant improvements and enrichments. However, this development has not been entirely organic. Rather, it has been comparable to 
expanding a house by constantly making various additions, each of which considers itself as an independent building retaining some relation to the main house, but not as a part of the whole.

Among these additions we find the "epidemiologic transition", the "second demographic transition", the "third demographic transition", as well as the "contraceptive revolution", the "cardiovascular revolution", etc. In essence, the theory became subdivided into separate parts, thus losing its conceptual unity in the interpretation of observed facts. The "subdivision" of one demographic transition into many separate transitions leads to the fact that the analysis of each of them yields the development of independent arguments detached from the "parent" theory's roots.

\section{THE EPIDEMIOLOGIC TRANSITION}

This is what happened, in particular, with the epidemiologic transition theory of A. Omran. The theory is commonly perceived as explaining the mechanisms and characteristics of the mortality reduction over the past centuries, but Omran's idea was different. His main article is called "The Epidemiologic Transition: A Theory of the Epidemiology of Population Change" [Omran 1971]. He interpreted the term "epidemiologic" as indicating the nature of mass phenomena, and believed that "many epidemiologic techniques that have heretofore been limited to the examination of health and disease patterns can be profitably applied as well to the exploration of other mass phenomena, such as fertility control" [Omran 2005: 731].

It is quite possible that the use of the expression "epidemiologic transition" in the article's title was a successful "marketing" strategy that allowed Omran to link his name firmly with this concept, but, in fact, his article provides an analysis of that very demographic transition, and, moreover, it is very insightful and, in my opinion, underestimated. His name is rarely mentioned in reviews on the history of the general theory of demographic transition.

Omran's work differs from other articles focused on the demographic transition in its more careful attention to the mortality reduction and in its pioneering study of this component of demographic transition. Meanwhile, he states from the very beginning that the epidemiologic transition theory was stimulated by "recognition of the limitations of demographic transition theory and of the need for comprehensive approaches to population dynamics" [ibid.: 732]; he moreover states that mortality is important in this context, because "the theory of epidemiologic transition begins with the major premise that mortality is a fundamental factor in population dynamics" [ibid.: 733]. "The basic strategy is not only to describe and compare the mortality transitions of various societies, but more importantly, to lend theoretical perspective to the process of population change by relating mortality patterns to demographic and socioeconomic trends" [ibid.: 755].

Omran constantly returns to the effects of mortality decrease on fertility, emphasizing that "improved infant and childhood survival tends to undermine the complex social, economic and emotional rationale for high parity for individuals and hence high fertility for society as a whole. As couples become aware of the near certainty that their offspring, particularly a son, will survive them, the likelihood of practicing family limitation is enhanced" [ibid.: 749]. Omran distinguishes three stages of changes in mortality during the demographic transition and states that at the third (last) stage, which he calls The age of degenerative and man-made diseases, "Mortality continues 
to decline and eventually approaches stability at a relatively low level. The average life expectancy at birth rises gradually until it exceeds 50 years. It is during this stage that fertility becomes the crucial factor in population growth" [ibid, p. 738].

The last phrase is more important than the previous two, but is commonly underestimated. Authors referring to the epidemiologic transition concept usually relate it to the study of mortality only. They pay tribute to A. Omran's conceptualization, which opened the way to rethinking the obvious fact of quantitative reduction in mortality in terms of the evolution in the composition of causes of death, as a result of which occurs "not only a shift from one dominant pathological structure to another", but simultaneously the "radical transformation process in ages at death" [Meslé, Vallin 2006: 247]. Moreover, they are trying to develop and modify the concept. Considering it to be related to the realities of the late 1960s and therefore to be obsolete, they propose to increase the number of stages [Olshansky 1986] or even principally change the approach to the classification, while at the same time changing the name of the concept in order "to include within the wider concept of health transition an initial phase (described by Omran) of life expectancy gains, attributed mainly to the decline in mortality due to infectious diseases, followed by a second phase dominated by the decline in cardiovascular diseases, leaving open the possibility of identifying later phases" [Ibid.: 250].

Whatever our attitude to all these proposals, it is evident that the stage at which "fertility becomes the crucial factor in population growth" remains where it was placed by Omran. In this sense, no subsequent shifts in mortality change anything fundamentally. Meanwhile, when it comes to "renaming" the epidemiologic transition, the question arises as to whether it is always justified to use concepts such as "transition" or "revolution". If any change is called a "revolution", then the concept of "evolution" loses its sense. Any transition or any revolution has a beginning and an end, but this does not mean that the end is not followed by further development. Is it right to put this unprecedented historical shift on a par with ordinary evolutionary changes, even if they are very important?

The concept of epidemiologic transition helps to understand the "anatomy" of historical changes in mortality as a key mechanism that triggers the entire demographic transition. In this sense, it is "embedded" in the general theory of demographic transition, becoming one of its parts. But, when taken outside the bounds of demographic transition analysis, it loses its heuristic power. There is no need of this concept to study subsequent changes in mortality.

At the same time one cannot deny that Omran's generalization contributes to a more structured approach to the study of mortality and its changes as a demographic phenomenon. It is obvious that these changes can be subdivided into stages, need periodization, and can be also characterized by their own "revolutions", etc. For example, Milton Terris distinguishes two epidemiologic revolutions [Terris 1985]. French demographers, as we have seen, emphasize the importance of the "cardiovascular revolution", while fertility researchers write about the "contraceptive revolution" [Leridon et al. 1987], etc. But these are "revolutions" of an absolutely different level. The attention given to them may be due to the general shift of demographic theory over the past half-century, noted by Caldwell, from a "grand theory" to a theory of short-term changes: "The times seemed to call for a theory applicable for the short-term rather than grand theory" [Caldwell 2006: 301]. 
There is no doubt that mortality researchers will understand by themselves what they can take from the epidemiologic transition theory and what they can omit. For our purposes, what is important is to recognize the epidemiologic transition as the key mechanism triggering a chain reaction of unprecedented changes in the reproductive strategy of humankind, as the first link in a single chain of transformations that make up the demographic transition.

\section{THE FIRST DEMOGRAPHIC TRANSITION}

In 1986, Lesthaeghe and van de Kaa formulated for the first time their concept of the "second demographic transition" [Lesthaeghe, van de Kaa 1986], which soon became widely known through a publication of D. van de Kaa's in the Population Bulletin of the United Nations in 1987 [van de Kaa 1987]. The second demographic transition will be discussed below, while now it is essential to explain what is meant by the "first" demographic transition, because no such concept existed until then.

As follows from van de Kaa's explanations at that time, as well as from Lesthaeghe's relatively recent article [Lesthaeghe 2010], the first demographic transition consists of a mortality reduction and a subsequent fertility decline to a level ensuring the zero population growth that occurred in Europe mainly before the Second World War [van de Kaa 1987: 4-5; Lesthaeghe 2010: 247]. (It should be noted that chronologically this roughly corresponds to what Omran called the third stage of the epidemiologic transition. However, he farsightedly did not mention "zero growth", merely stating that "during this stage fertility becomes the crucial factor in population growth").

But in addition to this purely descriptive characterization, which does not go beyond a mere statement of fact, van de Kaa's work also explains the mechanism of the "first transition to low fertility". Considering industrialization, urbanization, and secularization as "indirect determinants" of this transition, he states as follows: "The shift from family-based production to wage-paid labor that accompanied industrialization and urbanization reduced the economic utility of children. They could no longer serve as cheap labor for the parents' farm or business but instead required investment in schooling and training to give them a reasonable chance in life. As Australian demographer John Caldwell puts it, the "net flow of wealth" now favored children rather than parents. Moreover, a large number of children could mean the dissipation of family assets like land after the parents' death, so birth control became a sound strategy. Secularization reduced the influence of the churches and increased couples' willingness to practice family planning" [van de Kaa 1987: 5].

In this case, van de Kaa follows the established tradition. In another article [van de Kaa 2010] he gives an explanation of fertility decline as proposed by F. Notestein, one of the founders of the demographic transition theory, referring to his 1945 publication [Notestein 1945], which he calls "a classic article on the first demographic transition". According to Notestein, fertility started declining "in response to drastic changes in the social and economic setting that radically altered the motives and aims of people with respect to family size". These changes include "growing individualism", "rising levels of popular aspiration developed in urban industrial living", the function loss of the family, the expense of large families, the freedom from "older taboos", and 
"promoting the health, education, and material welfare of the individual child". As a result, Notestein comes to the conclusion that "the reduction of fertility requires a shift in social goals from those directed toward the survival of the group to those directed toward the welfare and the development of the individual".

There is no doubt that all the factors stated by Notestein, van de Kaa and many other authors played a role in reducing fertility. However, in order to list them, no theory is needed; they can be listed, though not in full, by any "man on the street". In Aesop's fable, the Lioness, when asked how many sons she had at birth, laughed and said: "Why! I have only one; but that one is altogether a thoroughbred Lion" [Aesop's Fables]. Polybius wrote: "Our men becoming perverted to a passion for show and money and the pleasures of an idle life, and accordingly either not marrying at all, or, if they did marry, refusing to rear the children that were born, or at most one or two out of a great number, for the sake of leaving them well off or bringing them up in extravagant luxury" [Polybius 1889: 37.9]. Does this mean that Aesop or Polybius can be considered as forerunners of the demographic transition theory? The internal logic of the demographic transition theory consists of, and only of, the fact that when it comes to reducing fertility, it is regarded as an inevitable stage of the chain reaction initiated by the unprecedented and irreversible decline in mortality, that is, as a necessary response to the demographic disequilibrium within a certain territory caused by this reduction.

Temporary and local cases of such disequilibrium have been observed previously. History knows four regulators that restore equilibrium [Livi Bacci 1995: 453-455]: (1) mortality; (2) emigration; (3) nuptiality (in particular the European marriage pattern as the "Malthusian" solution); (4) fertility (modern birth control as the "neo-Malthusian" solution). All of these regulators have also been tried when the reduction in mortality had become general and irreversible, but then it turned out that only the "neo-Malthusian" regulator, the least used in the past, was able to give an adequate response to the new challenges and provide a real transition to a more effective reproductive strategy of Homo sapiens.

No other explanations for present-day low fertility are required, and it would seem that all demographers familiar with the demographic transition theory know this. But, paradoxically, quite often the obvious relation between the decline in fertility and decline in mortality is barely seen in their reasoning, because they are focused on identifying the economic and social determinants of fertility decline, which they see in "changes in the social and economic setting": urbanization, the spread of modern education, changes in the economic and social status of women, etc.

Changes in the economic and social environment do of course occur, but their relation to the decrease in fertility is not so clear and unidirectional. These changes would be impossible under the previous demographic conditions, and they are as much a cause of reduced fertility as its consequence. Meanwhile, once started, all these modernization processes create socio-cultural mechanisms that promote the reduction of fertility through a change in the type of procreative motivation of more and more people. Yet these mechanisms are not specific; they do not just affect procreative behavior, they fundamentally change the predominant motivation of human behavior, and it is still unknown what factors cause this change more: political and industrial revolution, urbanization or "demographic revolution" proper as an independent response to a historical imperative. 
The main threshold separating controlled from uncontrolled fertility is precisely the type of motivation of human behavior, and the transition to controlled fertility requires a change in the type of motivation, but this very fact is constantly ignored by demographers. This can clearly be seen in the position, quite popular among demographers, of J. Caldwell, who is often referred to when explaining the causes of the reduction in fertility (as we saw, van de Kaa made such a reference). "In societies of every type and stage of development, fertility behavior is rational, and fertility is high or low as a result of economic benefit to individuals, couples, or families in its being so. Whether high or low fertility is economically rational is determined by social conditions: primarily by the direction of the intergenerational wealth flow. This flow has been from younger to older generations in all traditional societies" [Caldwell 1976: 355]. But then the compass needle turned 180 degrees, and the flow of wealth moved from parents to children, "Separating the earlier situation in which the net flow of wealth is toward parents and in which hence high fertility is rational and the later situation in which the flow is toward children and in which hence no fertility is rational" [ibid, p. 345].

How justified is such a universalization of economic rationality? Since the time of Max Weber there has been a distinction between two types of rational action: value-rational (wertrational) and instrumentally rational (goal-rational, zweckrational). In the first case we are dealing with "the actions of persons who, regardless of possible cost to themselves, act to put into practice their convictions of what seems to them to be required by duty, honor, the pursuit of beauty, a religious call, personal loyalty, or the importance of some "cause" no matter in what it consists. In our terminology, value-rational action always involves "commands" or "demands" which, in the actor's opinion, are binding on him" [Weber 1978: 25-26]. On the contrary, action is goal-rational "when the end, the means, and the secondary results are all rationally taken into account and weighed. This involves rational consideration of alternative means to the end, of the relations of the end to the secondary consequences, and finally of the relative importance of different possible ends" [Ibid].

The absolute predominance of value-rational motivation, characteristic of all pre-industrial societies, - following the canon, tradition, religious commandment - greatly restricted the freedom of individual choice in all fields. Unprecedented changes taking place in European societies, at least since the late eighteenth century, first required the general distribution of a different, goalrational motivation, making free choice both possible and necessary. Most discussions of these changes point to their economic, social, political or cultural components, without which "fertility would have remained largely in the domain of the sacred instead of that of individual freedom of choice" [Lesthaeghe 1983: 412]. However, it is ironic that the demographic component proper is usually not included in this list. Yet this component is likely to be the most important, because it is related to the most widespread practice when almost each family has to make a choice.

The idea of conscious birth control appeared prior to the recognition of free individual choice in this area. The "European" marriage pattern - marriage that is late and not universal [Hajnal 1965] - became a tool of such regulation for a little while, and Malthus - its fervent propagandist precisely for reasons of limiting offspring - vigorously rejected free procreative choice. "If it were possible for each married couple to limit by a wish the number of their children, there is certainly reason to fear that the indolence of the human race would be very greatly 
increased; and that neither the population of individual countries, nor of the whole earth, would ever reach its natural and proper extent" [Malthus 1826, App. II.14].

Over some time, the "European marriage pattern" recommended by Malthus (but not invented by him) seemed to be quite effective. In the late nineteenth century, fertility in Western Europe was much lower than, for example, in Russia, not familiar with the European marriage pattern, although birth control in most European countries was as uncommon as in Russia.

Yet, we should not forget that the first edition of Malthus's book appeared in the same year as the publication of Jenner's cowpox vaccination brochure (1798), when the unprecedented decline in mortality was just starting out. Further rapid progress in this direction forced European society to recognize that none of the three more or less familiar regulators - surges in mortality (beginning to disappear), late and non-universal marriage ("European marriage pattern"), and emigration - were able to restore the demographic equilibrium being increasingly distorted due to diminishing mortality. There remained a fourth possibility: the "neo-Malthusian" one.

Originally, neo-Malthusianism, not immediately so-named, combined a protest against late marriages with propaganda for birth control in marriage. Francis Place addressed his propaganda brochures to "spouses of both sexes", and surely did not mean to undermine the foundations of marriage and family of his day. On the contrary, he believed himself to be strengthening them by reducing the risk of extramarital affairs that were inevitable under the unnatural "moral abstinence" involved in late marriage. Robert Owen and other pioneers of birth control shared Francis Place's position.

However, could the family, once on the path of limiting its own procreation, remain the same as it was before? This is unlikely.

\section{THE SECOND DEMOGRAPHIC TRANSITION}

It is now clear that in the last hundred years the family has undergone truly enormous changes, which are apparently not yet completed. It is precisely on the transformation of the "classical" European family that the authors of the "second demographic transition" concept are focused. According to van de Kaa, the principal demographic feature of this "second" transition is the decline in fertility in European countries to a level well below replacement [van de Kaa 1987: 5]. Yet the focus is mainly on the changes accompanying this decline experienced by the family: cohabitation replacing traditional marriage; the center of family life being not the child's interests, but the interests of his or her parents ("shift from the era of child-king with parents to the era of royal couple with child"); contraception giving way to intentional conception as an element of parental self-fulfillment; and the unified standard form of family and household being replaced by pluralistic forms [ibid,: 11]. According to van de Kaa, the beginning of the "second demographic transition" can be dated from the mid-1960s; today, the list of changes can be significantly expanded and detailed. Yet, in this case, we are interested not in the indisputable fact of the transformation of family and family relations, but in its explanation.

If, when discussing the "first demographic transition", van de Kaa, as we have seen, connected it to industrialization, urbanization and secularization, then for the "second 
demographic transition" he looks for other determinants, otherwise it's impossible to speak not only of the next stage of a developing process, but of a new, fairly independent phenomenon.

Hence, it is necessary to pinpoint the specific determinants of the "second" transition. Van de Kaa characterizes them as follows: "Rising incomes and the economic and political security which democratic welfare states offer their populations have helped to trigger a "silent revolution". ...An individual's sexual preferences are accepted for what they are, and decisions on cohabitation, divorce, abortion, sterilization and voluntary childlessness are largely left to the discretion of the individuals and couples involved" [van de Kaa 1996: 425]. Lesthaeghe also notes that, starting with van de Kaa's publication in 1980, both van de Kaa and he - referring in particular to Philippe Ariès' article [Ariès 1980] - have pointed repeatedly to the changing motivation of having children; the "child-centered" family of the era of the first transition is being replaced by the family oriented towards the parents' self-realization [Lesthaeghe 2010: 213].

Thus, the "trigger" is found again in economic, social and political spheres, rather than in the chain of successive events defined by the demographic changes. It seems to me that if we start from the internal logic of the demographic transition theory, then the "trigger" should be sought in these very changes at the beginning of the chain, meaning it was pulled long before the 1960s, the date assumed to be the beginning of the "second demographic transition". Even if we do not talk about the epidemiologic transition which initially led to all the changes in the demographic behavior of people, then the transition to the "neo-Malthusian" birth control left no chance of preserving the traditional family unchanged.

There is an obvious correlation between changes in family morals, status and forms of marriage and family, social roles of parents, in all that can be called the "demographic behavior" of people, on the one hand, and the declining influence of religious norms, the growth of individualism, people's desire for self-realization, the distribution of "post-materialistic values", etc. on the other hand, as is written by the authors of the concept of the "second demographic transition". Yet the question is as follows: what is the cause and what is the consequence of these changes?

In order to explain why people trace their individual life trajectories in a different way now, no special economic or sociological arguments are needed; they are superfluous. Even without them, it follows from the basic postulate of the demographic transition theory on the changing type of demographic equilibrium that the previous rigid social requirements for such trajectories are losing their meaning in a quite natural way. The return to equilibrium is impossible without a complete reconstruction of the whole pattern of demographic behavior: "It is precisely the pattern of demographic behavior, as well as the pattern and methods of social control over it that underwent a genuine revolution, which led to the formation and establishment of a new type of fertility" [Vishnevsky 2005: 99].

For many centuries in pre-industrial Europe, and evidently in all mature agrarian societies, the cornerstone of family life and family morality was the inseparable unity of three kinds of behavior: sexual, matrimonial and procreative [ibid, p. 98-99]. It was of course a normative unity that was often violated in real life. Nevertheless, such violations were always treated as reprehensible exceptions to the rule, and as marginal forms of behavior condemned by the dominant culture; in general daily life, all social strata held to normative cultural guidelines. 
The transition to family-controlled fertility made the preservation of this unity impossible and "the disconnection between marriage and procreation", which Lesthaeghe considers as a manifestation of the second demographic transition [Lesthaeghe 2010: 211], inevitable. The autonomization of procreative behavior is the very essence of the demographic transition at its neo-Malthusian stage; this autonomization naturally entails the separation of all three previously inseparable behaviors: sexual, marital and procreative. Having become relatively independent, these three kinds of behavior started to make their own paths in each individual biography, creating the possibility of infinite variability in individual life courses and, moreover, making this variability inevitable.

Hence, the "second demographic transition" is not a separate process with its own independent determinants, but only one of the natural stages of demographic transition, one of the phases of the chain reaction launched by the decrease in mortality.

Societies, which have reached this stage of the demographic transition, find themselves in a new historical situation. They are inevitably entering a period of searching, in which hundreds of millions or even billions of families over several generations are participating, gradually overcoming the inertia of the past, abandoning existing norms and developing new institutional forms and new cultural regulation of the individual, private and personal life of people and their individual life paths. Constantly and pervasively emerging attempts to resist such changes by appealing to the experience of the past are futile, because this past no longer exists.

The search is being conducted in the only possible way - through trial and error, that is, by testing a wide variety of possible adaptations to the new demographic and social realities in a search involving the socio-cultural selection of the most competitive, efficient forms and norms [Vishnevsky 1986: 239-242; Vishnevsky 1991: 267].

According to statistics and research data, European countries at least, the first to experience the demographic transition's effect, are seeing more frequent and earlier initiation of premarital sexual relationships in no way related to the intention of getting married. Along with the customary and only type of marriage that begins with a wedding and official registration and lasts until one of the spouses dies, we now see the spreading of cohabitations, "partnerships" that begin without registration and then either split up, are registered as a marriage, or continue without registration. There is an increase in remarriages after a formal divorce, whether the marriage was registered or after widowhood, or after termination of a previous officially unregistered cohabitation. Remarriages, even more often than first marriages, can remain unregistered, yet still be considered as marriages. Other "non-standard" forms of cohabitation are appearing as well. There is nothing new in any of these forms; almost all of them have existed at different times and in different cultures. The novelty lies in the fact that they exist simultaneously in the same society and receive cultural approbation.

Searches are carried out not only along the "marriage partners" axis, but also along the "parent-child" axis. What first draws attention is the low fertility, but in fact, the changes are much more diverse. People are looking for a more convenient time to have children, the number of single-parent families is increasing, the proportion of children born out of wedlock is growing rapidly, more and more children are appearing who seem to belong to several families at once, because their parents' divorce and remarriage are no longer considered a disaster, and children 
keep contacts with both parents. The separation of biological from social parenthood is no longer exotic, and the concept of "parenthood" is blurred or transformed.

All this new diversity requires constant observation and study. The task of this article is only to emphasize the primordial demographic nature of these changes and their fundamental relation to the transition of humankind to a new reproductive strategy.

Fertility is decreasing around the world, and the family is being subjected to an unprecedented transformation, not because women have started to study and get jobs, nor because they are seeking self-realization, using modern contraceptives or refusing to tie themselves forever to untested partners. On the contrary, all that became possible owing to the fact that it is no longer necessary to ensure the continuous birth of children, a huge proportion of which did not survive. Carrying out one's "demographic duty" does not require nearly as much time and effort as in the past; individual freedom has sharply expanded. Unfettered by objective demographic requirements, each person has such a variety of choices for his or her life path as has never before been seen.

\section{THE THIRD DEMOGRAPHIC TRANSITION}

The relatively new concept of the "third demographic transition" is one more example of a selfproclaimed autonomous addition to the building of the theory of demographic transition. As with the "second demographic transition", it is not the term that raises doubts - in both cases it points to a very important specific stage of the unified demographic transition, thus contributing to its understanding - but its "isolated" interpretation.

According to David Coleman, the third demographic transition is, first of all, a change in the ethnic, cultural, etc. composition of the population of the host countries due to immigration. The prerequisites for such immigration arise due to the low fertility in the host countries, whose populations are not reproducing. Such countries have to compensate for the loss of population by accepting a large number of migrants, thus giving rise to the phenomenon of the "third demographic transition" [Coleman 2006].

Coleman emphasizes that, in contrast to the first one, the third demographic transition is not universal: it affects only developed countries with low fertility, and the resulting changes are not symmetrical. The population composition of the developed world will become similar to that of the developing world, but not vice versa [Coleman, 2006: 428]. Yet, he believes that this course of events is not inevitable, because the forecasts predicting a huge inflow of migrants are "not written in stone", and the right policy will help to avoid them [Coleman 2006: 417-419].

Of course, changes in ethnic composition in developed and developing countries due to migration from the "South" to the "North" will be asymmetrical, but the idea of the third demographic transition in its current form is asymmetrical as well. Although Coleman notes the incompleteness of the demographic transition in the "South" as one of the driving forces of the migration process on which the "third transition" concept is based, in general he pays very little attention to this "driving force". He is sure that the example of the authorities in the Netherlands or Denmark trying to constrain immigration into their countries shows a way of slowing down the 
"third transition" and thus, evidently, believes that the "driving force" is not too significant. His whole concept reflects the understandable concern of the developed countries in relation to growing migration pressure from the developing world, but scarcely considers the global demographic situation making this pressure inevitable. But this situation, in turn, is a direct consequence of, or more precisely, a natural stage of the global demographic transition, that is, of a gigantic mutation of Humankind changing its reproductive strategy.

As is noted by Coleman, "Neither transition concept considers migration explicitly, or any consequent changes in the composition of populations, although van de Kaa (1999) assumes an increase in immigration to be a natural indirect consequence of the low fertility of the recipient countries. On the other side of that equation, emigration tends to be highest at the peak of population growth in the middle of the transition, as with Europe in the nineteenth century and the developing world today (Ortega 2005)" [Coleman 2006: 402].

We can agree that the demographic transition theory in its established form does not give much consideration to migration and focuses on the change in the fertility-mortality ratio. However, it does not "close the door" to including migration among the key variables of transition.

As was mentioned earlier, migration is one of the regulators activated by demographic disequilibrium. At the same time, it is one of the most important factors in human history which formed the current pattern of distribution of humans on Earth, including their racial, ethnic and linguistic diversity. Coleman knows the history of migrations very well. He refers to the "change in population composition ... in Eurasia and elsewhere in the first millennium AD and earlier from Northern Europe, Central Asia and Arabia, with the expansion of Mongols and Ottomans as the last major examples" [ibid.: 419] as well as to the role of the migration regulator during the European population explosion of the nineteenth century, when overseas migrations simultaneously weakened the demographic tension in Europe and led to the populating of the United States and other new states with a population of European origin.

However, the situation found in the world today has no precedents either in the scale and speed at which the disequilibrium arose that led to the unprecedented population explosion, or in geographical coverage. In fact, we can speak of an almost instantaneous (in historical terms) globalization of the demographic transition. At this stage, the inclusion of the migration regulator, when other regulators are either unacceptable (increased mortality) or insufficient (decreased fertility), to restore equilibrium rapidly is quite natural, and in no way contradicts the logic of the demographic transition theory.

It is precisely in the globalization of the demographic transition that the new phase consists, a phase which could be called the "third demographic transition" but which should not be reduced to just the change in the population composition in the host countries, even though such a change can really be observed ${ }^{2}$. Its essence lies in the transformation of the world's population into a

2It is curious that this very fact, the "creolization of cultures", which the migration researchers write about [Okolski 1999: 28] is considered by van de Kaa as one of the manifestations of the second demographic transition [van de Kaa 2003: 32-33]; it is moreover quite logical, because ethnically and religiously mixed marriages and the multiple identities of children resulting from such marriages naturally fit the variegation found in individuals' private lives. 
system of communicating vessels, where all demographic processes are interrelated and hardly understandable from the perspective of any one component of this system.

In Coleman's scheme, one of the main factors of immigration to Europe is a fertility falling below the replacement level in European countries. Both Coleman and, as we have seen, other theorists of the demographic transition seek to explain this fall in the economic, social and cultural changes occurring in these countries. Our objection is basically that such explanations are redundant, because the fertility decline is predetermined by the reduction in mortality and the need to restore demographic disequilibrium. Such an objection could always run up against the counterargument that the decline of fertility does not stop after reaching the replacement level, but falls below it. This argument is not only stated, but is occasionally interpreted as a sign of failure of the demographic transition theory [Vallin 2005; Marchal, 2008].

Such reasoning may seem convincing only within the framework of the logic which may be metaphorically described as "Westphalian", referring to the Westphalian system of international relations established in Europe in the eighteenth century and which became the triumph of state sovereignty principles. These principles are consistent with "state-centric" thinking demographers, who consider that the demographic transition theory should be justified within the framework of the national borders of different states or, in extreme cases, groups of states.

Meanwhile, no country should be regarded as a "closed system", within which the demographic transition can occur regardless of what is happening outside. Only the whole population of the Earth can be considered such a closed system. At a global scale, fertility is still significantly higher than the replacement level, and the disrupted equilibrium is still not restored. But even if the fertility-mortality equilibrium is restored at the global level - for example, by 2100 , as is suggested by the more likely scenarios of the latest UN projections - this does not signify the restoration of equilibrium between the number of the Earth's inhabitants (assuming that it will reach 10-11 billion people by that time) and the life support resources of our planet. "From the standpoint of the self-protection of human civilization, it would be much better to arrive at a stage of population decline. If we rule out such a reduction due to a rise in mortality, then achieving fertility below replacement level is the only mechanism that can lead to such an evolution" [Vishnevsky 2004: 274].

In the framework of this logic, which does not contradict the general logic of the demographic transition as a process of adaptation of the world demographic system to the new reproductive strategy of Humankind, the low fertility in the developed countries of the North and growing migration flows from the South to the North are interrelated not as cause and effect, but as juxtaposed links of a single chain at this stage of demographic development - that of the globalized demographic transition.

On the one hand, low "Western" fertility is not at all indicative of the decline and crisis of modern "Western" civilization, as is often thought; on the contrary, it is proof of its high adaptive capabilities. By paving the way for the unprecedented worldwide reduction in mortality, the developed countries are paving the way for low fertility as well, without which one of the greatest human achievements - low mortality - is becoming a serious threat to humanity" [Vishnevsky, 2008: 85]. Meanwhile, low fertility could be viewed quite negatively in developed countries, including Russia, and could indeed provoke serious problems for them (in particular, those which 
Coleman writes about). But no country is in condition to fight against it, because "the implicit objective logic of global survival proves to be more important than an egoistic logic of individual nations. If this hypothesis is correct, the main determinants of the fertility decline below replacement level in all industrialized countries do not have their most profound roots in the specific life conditions of those countries. Such a decline is a part of a global demographic process that is being driven by its own inherent forces" [Vishnevsky 2004: 274]. Eventually, all countries follow the pioneers of low fertility. China was just the first case, and now is far from being the only one.

On the other hand, however, given the considerable time required to restore the global demographic equilibrium with the help of fertility decline, there will inevitably be a fairly long period during which international migration will play its usual historical role of a balancing redistribution mechanism.

Of course, this stage will not be easy. We know what impact "The Great Migrations" of the first millennium CE had on Europe's population make-up and history. Today it seems that those migrations were enormous, and they really were enormous for that time, when the world's population numbered about 200 million people. But in the early twenty-first century the rapidly growing number of international migrants already exceeded 200 million [UN 2013a: Table 1], and most likely this is just the beginning. According to UN estimates, net migration from developing to developed countries increased from 6.5 million in 1975-1980 to 17.4 million people in 20052010. [UN 2013b: fileMIGR/2]. How will events develop further? UN projections predicting a reduction in the population flow from developing to developed countries all the way up to its cessation by the end of the century (see diagram) seem utopian; nothing portends such a reduction yet. These projections are based more on the current state of public opinion in developed countries than on a real evaluation of the future. 


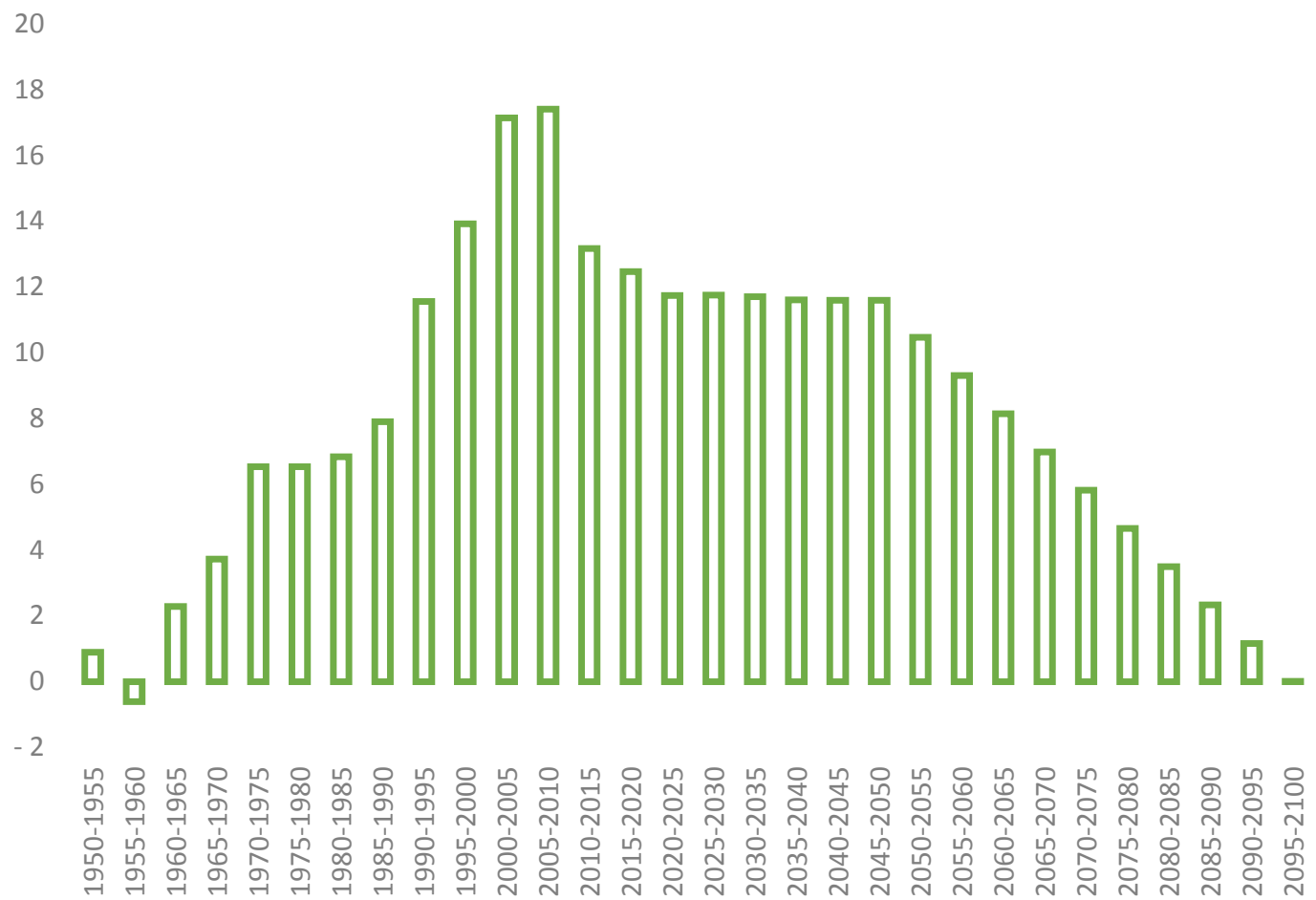

\section{Net migration from developing to developed countries, by UN estimates and projections, 1950-2100, millions}

\section{Source: [UN 2013b: file MIGR/2]}

The depopulated countries of the "North" will always need an inflow of population, while the overpopulated "South" will always be ready to meet any demand for migrants. However, the demographic masses of the "North" and "South" are unequal: the migratory pressure from the "South" will always exceed the needs of the "North", as well as its ability to manage the increased supply, and the more time passes, the truer that will be. At present, it is hard to imagine the result of this collision, but that the current phase of the "globalized demographic transition" creates very serious problems for the world, and that their solution will be much more complex than both Coleman and the author of this article would like, can hardly be in doubt.

\section{CONCLUSIONS}

The main objective of this article is to emphasize the scope and independence of the demographic changes the world is facing. Adolphe Landry was the first to speak about these changes; he called them the "demographic revolution" [Landry 1933; Landry 1934; Landry 1987], thus implicitly pointing to the historical extent of these changes. By the 1940s, discussion of these changes had shifted to the United States, where the term "demographic transition" was introduced and, according to van de Kaa, "As a consequence, its historical depth and ideational dimension diminished, while the process of modernization and its economic aspects were emphasized more strongly". Eventually, the term "demographic transition" prevailed, although, according to van de $\mathrm{Kaa}$, it is hard to say whether the term "revolution" was rejected consciously or the term 'transition' prevailed 'because it had more international appeal and more scholars could more easily consult American rather than French demographic literature" [van de Kaa 2010]. 
It is hardly worth renewing the debate about the terms now, but it should be noted that the term "revolution" points to a deeper historical context. This suggestion is also confirmed by van de Kaa, who noted that the term was not chosen by Landry accidentally, and that he seemed to put this almost unnoticed revolution on a par with the French political revolution, marked by a number of spectacular events [ibid]. This fact has also been noticed by other authors, for example, by Zdenek Pavlik, who put the demographic revolution on a par with another great historical event: "The industrial revolution in economic development is consistent with the demographic revolution in population development" [Pavlik 1964: 38]. According to Pavlik, "The demographic revolution is a component of the complex historical process involving many facets, and, far from being their passive product, plays an independent and important role in this process" [Pavlik 1970: 51-52].

It seems to me that the term "revolution" is more consistent with the absolutely special, fundamental role of the demographic transformation we are observing. If we recognize that it really marks the transition to a new reproductive strategy of Homo sapiens, then we should also recognize the fact that it is superior to any political or economic revolution in its universal significance, its consequences and the global risks it generates.

Yet, the problem is of course not in the term. The problem is in understanding and recognizing the unity and universality of this transformation, the predetermined nature and inevitability of its stages and of those truly unprecedented challenges to which it requires a response. Hence, there is one more objective in this article: comparing two views of the demographic transition (demographic revolution). This transition can be regarded as a selfdeveloping "chain reaction" which, once started, becomes irreversible, passing through different stages, each of which is predetermined largely by the previous stage and predetermines the subsequent stage until the completion of the whole process. But it is also possible to regard the transition stages, as is commonly done, as a sequence of observed changes, each of which has its own "non-demographic" determinants (economic, social, etc.). Hence, these stages are not obligatory: they can be observed in some countries and be absent in others, be observed in Europe and be absent in Asia, etc.

Now researchers, and especially politicians, seem to be trying to ignore the unity of the powerful historical flow. Scientific consciousness alternates with conventional "common sense", focusing on certain areas of this flow, occasionally even on small and random branches of it, offering recipes whose only virtue lies in the fact that they are readily understood by "the man on the street" and can thus reduce his anxiety. Public opinion often does not see the relation between global demographic changes and the short-term problems of an individual family or a separate country. Meanwhile, history is doing its job.

\section{REFERENCES}

Aesop's Fables. Translated by George Fyler Townsend. eBook,

URL: http://www.gutenberg.org/files/21/21-h/21-h.htm\#link2H_4_0042

Ariès P. (1980). Two successive motivations for the declining birth rate in the West // Population and Development Review. 6(4): 645-650. 
Caldwell J.C. (1976). Toward a restatement of demographic transition theory // Population and Development Review. 2(3-4): 321-366.

(2006). Demographic transition theory. Springer.

Chesnais J.-C. (1986). La transition démographique //INED. Travaux et documents. Cahiers No.113. PUF.

Coleman D. (2006). Immigration and ethnic change in low-fertility countries: a third demographic transition // Population and Development Review. 32(3): 401-446.

Cowgill D.O. (1970). Transition theory as a general population theory // Social Demography. N.J.: Prentice-Hall, Englewood Clifs: 627-633.

Demeny P. (1972). Early fertility decline in Austria-Hungary: A lesson in demographic Transition // D. V. Glass and R. Revelle (eds.), Population and Social Change. London and New York: Edward Arnold:153-172.

Engels F. (1884). The origin of the family, private property and the state. Preface to the first edition // Karl Marx, Frederick Engels. Collected Works. Vol. 26. Online Version: Marx/Engels Internet Archive (marxists.org) 1993, 1999, 2000.

URL: https://www.marxists.org/archive/marx/works/1884/origin-family/preface.htm

Guzevatyy Y.N. [Гузеватый Я.Н.] (1980). Demografo-ekonomicheskiye problemy Azii [Demographic and economic problems of Asia]. Moskva: Nauka.

Hajnal J. (1965). European marriage patterns in perspective // D.V.Glass and D.E.C. Eversley (eds.), Population in history. London, 1965.

Kautsky K. [Каутский К.] (1923). Razmnozheniye i razvitiye v prirode i obshchestve [Reproduction and development in nature and society]. Sochinenia [Collected works], Vol.12. Moskva-Petrograd: Gosizdat.

Landry A. (1909). Les trois théories principales de la population. Scientia // Adolphe Landry. La révolution démographique. Études et essais sur les problèmes de la population. INED. 1982: 169-192.

(1933). La révolution démographique // Economic Essays in Honour of Gustav Cassel, London: George Allen \& Unwin, 1933: 357-367.

(1934). La Révolution démographique. Études et essais sur les problèmes de la population. Paris. Librairie du Recueil Sirey.

(1987). [Adolph Landry on the Demographic Revolution]. English translation of [Landry 1933] // Population and Development Review, 13 (1987): 713-740.

Leridon H. et al. (1987). La seconde révolution contraceptive: La régulation des naissances en France de 1950 à 1985 // Paris, INED. Travaux et documents. Cahier No.117.

Lesthaeghe R., D.J. van de Kaa (1986). Twee demografische transities? // D.J. van de Kaa, R. Lesthaeghe (eds), Bevolking: Groei en Krimp. Deventer: Van Loghum Slaterus: 9-24.

Lesthaeghe R. (1983). A century of demographic and cultural change in Western Europe: An exploration of underlying dimensions // Population and Development Review. 9(3): 411-435. (2010). The unfolding story of the second demographic transition // Population and Development Review. 36(2): 211-251.

Livi Bacci M. (1995). À propos de la transition démographique // Transitions démographiques et sociétés. Chaire Quetelet 1992. Sous la direction de D. Tabutin, T. Eggerickx, C. Gourbin. Louvain-la-Neuve: Academia - L'Harmattan : 449-457. 
MacArthur R.H., E.O. Wilson (1967). The Theory of Island Biogeography. Princeton.

Malthus Thomas Robert (1826). An Essay on the Principle of Population. 6th edition. App. II.14. URL: http://www.econlib.org/library/Malthus/malPlong41.html\#Appendix II

Marchal C. (2008). De la théorie géocentrique à la transition démographique : Comment meurt une théorie scientifique. URL: http://desiebenthal.blogspot.fr/2008/11/krach-le-suicide-dumonde-jean.html (accessed: 22.04.2014).

Marks K., F. Engels [Маркс К., Ф. Энгельс] (1948). Izbrannyye proizvedeniya v 2 tomakh. Tom II [Selected Works in 2 volumes. Volume II]. Moskva: Gospolitizdat.

Meslé F., J. Vallin (2006). The health transition: Trends and prospects // Caselli G., J. Vallin, G. Wunsch. Demography. Analysis and Synthesis. A Treatise in Population Studies. Elsevier, Volume 2, Chapter 57.

Notestein F. (1945). Population - the long view // T.W. Schultz, ed. Food for the World. Chicago: Chicago University Press: 37-57.

Okólski M. (1999). Migration pressures on Europe // Working papers of the Institute for Social Studies, University of Warsaw. Seria: Prace migracyjne.

Olshansky D.J., A.A. Brian (1986). The fourth stage of the epidemiologic transition: the age of delayed degenerative diseases // The Milbank Quarterly. 64(3): 355-391.

Omran A.R. (1971). The epidemiologic transition: a theory of the epidemiology of population change // The Milbank Memorial Fund Quarterly. 49(4). Pt.1.

(1977). Epidemiologicheskiy aspekt teorii yestestvennogo dvizheniya naseleniya [Epidemiological aspects of the theory of natural movement of the population] // D.I. Valentey, A.P. Sudoplatov, eds. Problemy narodonaseleniya. O demograficheskikh problemakh stran Zapada [Population Problems. On the demographic problems of the West]. Moskva: Progress: 57-91.

(2005). The epidemiologic transition: a theory of the epidemiology of population change // The Milbank Quarterly. 83(4): 731-757.

Pavlik Z. (1964). Nástin populačniho vyvoje světa. [Outline of the World population development]. Praha.

(1970). Problemy demograficheskoy revolyutsii [Problems of demographic revolution] // Studia demograficzne [Demographic studies]. No.22-23.

Polybius (1889). Histories, 37.9. London, New York. Macmillan. 1889. Reprint Bloomington 1962. URL: http://www.perseus.tufts.edu/hopper/text;jsessionid=31636ED636B094DFFC1D5E6CAC7A C25D?doc=Perseus\%3Atext\%3A1999.01.0234\%3Abook\%3D37\%3Achapter\%3D9

Reher D.S. (2011). Economic and social implications of the demographic transition // Population and Development Review. 37 (Supplement): 11-33.

Terris M. (1985). The changing relationships of epidemiology and society: The Robert Cruikshank lecture // Journal of Public Health Policy. 6(1): 15-36.

UN (2013a). Department of Economic and Social Affairs. Trends in International Migrant Stock: The 2013 revision.

UN (2013b). Department of Economic and Social Affairs, Population Division. World Population Prospects: The 2012 Revision. CD-ROM Edition.

Van de Kaa D.J. (1987). Europe's second demographic transition // Population Bulletin. 42(1). 
(1996). Anchored narratives: The story and findings of half a century of research into determinants of fertility // Population Studies. 50(3): 389-432.

(2003). Never a dull moment: on research prospects for Polish demographers // D.J. van de Kaa Doctor Honoris Causa of the Warsaw School of Economics.

--------- (2010). Demographic transitions // Yi. Zeng, ed. Encyclopedia of life support systems (EOLSS). Demography. Vol.1. Oxford: Eolss Publishers: 65-103.

Vishnevsky А. [Вишневский А.Г.] (1973a). Demograficheskaya revolyutsiya [The demographic Revolution] // Voprosy filosofii [Problems of Philosophy]. No.2: 53-64.

[Wischnevski A.G.] (1973b). Die demographische Revolution // Sowjetwissenschaft. Gesellschatswissenschaftliche Beiträge. Berlin. No.6. 633-645.

- (1974a). The demographic revolution // Population Problems. Issue Two. Problems of the Contemporary World. Moscow. 1(26) : 116-129.

[Vichnevski A.] (1974b). La révolution démographique // Problèmes de la population. IIe livraison. Problèmes du monde contemporain. Moscou. 1(25) : 121-133.

--------- [Višnevskij A.G.] (1980). Die demographische Revolution // Theorie und Methode III. Demographie. Einführung in die marxistische Bevölkerungswissenschaft. Frankfurt am Main. Herausgegeben vom Institut für Marxistische Studien und Forschungen (IMSF): 4045 .

[Вишневский А.Г.] (1986). Protsessy samoorganizatsii v demograficheskoy sisteme [Self-organization of the demographic system] // Sistemnyye issledovaniya.

Metodologicheskiye problemy [Systems study. Methodological problems]. Yezhegodnik (Yearbook). 1985. Moskva: Nauka: 233-245.

(1991). Demographic revolution and the future of fertility: a systems approach // W. Lutz, ed. Future demographic trends in Europe and North America. London: Academic Press: 257-280.

(2004). Replacement migration: Is it a solution for the Russian Federation? // Policy Responses to Population Decline and Ageing. Population bulletin of the United Nations. Special Issue. No.44/45: 273-287 (ST/ESA/SER.N44/45).

[Вишневский А.Г.] (2005). Demograficheskaya revolyutsiya [The demographic Revolution] (1976) // Izbrannyye Demograficheskiye Trudy [Selected demographic works]. Vol.1. Demograficheskaya teoriya i demograficheskaya istoriya [Demographic theory and demographic history]. Moskva: Nauka: 3-214.

Weber M. (1978). Economy and society. An outlook of interpretive sociology / Guenter Roth, Claus Wittich, eds. Univ. of California Press. 